\title{
Serum and Red Blood Cell Folate Testing on Hospitalized Patients
}

\author{
Anthony C. Breu, MD ${ }^{1,2 *}$, Jesse Theisen-Toupal, MD ${ }^{2,3}$, Leonard S. Feldman, MD ${ }^{4,5}$
}

${ }^{1}$ Medical Service, Veterans Affairs Boston Healthcare System, West Roxbury, Massachusetts; ${ }^{2 H a r v a r d}$ Medical School, Boston, Massachusetts; ${ }^{3}$ Division of General Medicine and Primary Care, Beth Israel Deaconess Medical Center, Boston, Massachusetts; ${ }^{4}$ Divisions of General Internal Medicine and Pediatrics, Johns Hopkins Hospital, Baltimore, Maryland; '5Johns Hopkins School of Medicine, Baltimore, Maryland.

The "Things We Do for No Reason" (TWDFNR) series reviews practices which have become common parts of hospital care but which may provide little value to our patients. Practices reviewed in the TWDFNR series do not represent "black and white" conclusions or clinical practice standards, but are meant as a starting place for research and active discussions among hospitalists and patients. We invite you to be part of that discussion.

\section{CASE PRESENTATION}

A 65-year-old man is admitted with pneumonia. Review of the medical record reveals a persistent macrocytic anemia (hematocrit 29\%, hemoglobin $9.3 \mathrm{~g} /$ $\mathrm{dL}$, mean corpuscular volume [MCV] $105 \mathrm{fL}$ ) with a low reticulocyte count and normal peripheral blood smear. The provider contemplates ordering a serum folate or red blood cell (RBC) folate test to workup the persistent macrocytic anemia.

\section{BACKGROUND}

Folate is a water-soluble B vitamin essential for the synthesis of DNA and for converting homocysteine to methionine. Folate deficiency is causally linked with both neural tube defects and megaloblastic anemia. Low levels of folate are associated with cardiovascular disease, colon cancer, neuropathy, depression, hypercoagulability, and cognitive decline, though there is a paucity of evidence showing causation or risk reduction with folate supplementation. ${ }^{1}$ In patients with inadequate folate intake, the earliest sign is a decline in serum folate levels, followed by a fall in RBC folate levels. Only weeks later do macrocytosis, megaloblastic bone marrow, and finally anemia occur. ${ }^{2}$ Given that humans are unable to synthesize folate and are therefore dependent on dietary sources, those with inadequate intake or absorption are at risk of folate deficiency.

\footnotetext{
*Address for correspondence and reprint requests: Anthony C. Breu, MD, VA Boston Healthcare System, Medical Service (111), 1400 VFW Parkway, West Roxbury, MA 02132; Telephone: 857-203-5111; Fax: 857-203-5549; E-mail: anthony.breu@va.gov

Additional Supporting Information may be found in the online version of this article.

Received: December 4, 2014; Revised: January 29, 2015; Accepted: March 3, 2015

2015 Society of Hospital Medicine DOI 10.1002/jhm.2385

Published online in Wiley Online Library (Wileyonlinelibrary.com).
}

\section{WHY FOLATE TESTING IS ORDERED}

In hospitalized patients, the most common indication for folate testing is anemia, either with or without macrocytosis. ${ }^{3,4}$ Given that at least $10 \%$ to $15 \%$ of hospitalized patients are anemic, ${ }^{5,6}$ it is unsurprising that folate testing is frequently performed. Despite the link between folate deficiency and megaloblastic anemia, $>85 \%$ of patients evaluated for folate deficiency have normocytic or microcytic anemia. ${ }^{3,4}$ In addition, a study found that $30 \%$ of all folate testing was performed not as part of an anemia workup but in the evaluation of other comorbidities (eg, dementia and altered mental status) that are not causally linked to folate deficiency. ${ }^{7}$

\section{WHY THERE IS NO REASON TO ORDER FOLATE TESTING}

There are 2 reasons why testing hospitalized patients for folate deficiency does not contribute value: (1) the poor characteristics of the tests used and (2) the low prevalence of folate deficiency in the postfortification era.

There is no accepted gold standard for the diagnosis of folate deficiency, though biological assays are considered more accurate than the now more commonly used protein binding assays. ${ }^{8}$ The lack of a gold standard limits the ability to fully quantify the sensitivity and specificity of either serum or RBC folate testing, though falsely low and high serum folate results can be seen. Falsely low serum levels (false positives) are found with heavy alcohol use and with certain anticonvulsant or antineoplastic drug use. ${ }^{9}$ The low levels in these patients indicate low serum folate but do not necessarily reflect tissue stores. Serum folate levels may fall rapidly within a few days of the start of low dietary folate intake, resulting in low serum folate levels that also do not represent true folate deficiency. ${ }^{10}$ On the other hand, intake of folate-through a meal or ingestion of an oral supplement-directly preceding evaluation of serum folate can lead to falsely elevated levels (false negatives). ${ }^{10}$

Although RBC folate reflects body stores and is largely unaffected by diet, the available tests also lack sensitivity and specificity. ${ }^{11}$ Furthermore, serum folate levels and RBC folate levels correlate well. ${ }^{12}$ Because $\mathrm{RBC}$ folate testing is more expensive than serum folate testing, has results that correlate well with serum folate testing, and is without significantly better test characteristics, there is no added value to using 
TABLE 1. Rates of Low Serum and Red Blood Cell Folate Levels in the United States and Canada in the Post-Folic Acid Fortification Era

\begin{tabular}{|c|c|c|c|c|c|c|c|c|c|}
\hline \multirow[b]{2}{*}{ Author, Study Year } & \multirow{2}{*}{$\begin{array}{l}\text { Year of } \\
\text { Testing }\end{array}$} & \multirow[b]{2}{*}{ Country } & \multirow[b]{2}{*}{ Population } & \multicolumn{3}{|c|}{ Serum Folate } & \multicolumn{3}{|c|}{ Red Blood Cell Folate } \\
\hline & & & & Patients (n) & Samples (n) & Low (\%) & Patients (n) & Samples (n) & Low (\%) \\
\hline Latif et al., 2004 & 2001 & United States & Inpatient/outpatient & 4,315 & 4,689 & 1.6 & 1,215 & 1,335 & 1.2 \\
\hline Shojania et al., $2010^{19}$ & 2001 & Canada & Inpatient/outpatient & & 2,154 & 0.5 & & 560 & 0.7 \\
\hline Ashraf et al., $2008^{7}$ & 2002 & United States & Inpatient/outpatient & 980 & 1,007 & 0.4 & & & \\
\hline Gudgeon et al., $2014^{20}$ & 2010 & Canada & Inpatient & & & & & 2,563 & 0.2 \\
\hline Theisen-Toupal et al., $2013^{3}$ & 2011 & United States & $\begin{array}{l}\text { Inpatient/emergency } \\
\text { department }\end{array}$ & 1,944 & 2,093 & 0.1 & & & \\
\hline
\end{tabular}

RBC folate testing as compared to serum folate testing.

In addition to the issues with available diagnostic tests, numerous studies now indicate that the rate of folate deficiency in the United States is exceptionally low. This is largely driven by the United States Food and Drug Administration's mandate that all grain products be fortified with $0.14 \mathrm{mg}$ of folic acid per gram of grains. ${ }^{13}$ Fortification has been overwhelmingly successful at increasing folic acid intake ${ }^{14,15}$ and reducing the incidence of neural tube defects. ${ }^{16}$ Although the serum and RBC folate tests are prone to inaccuracies for an individual patient, population trends postfortification, coupled with the data on intake and rates of neural tube defects, make a strong argument that the prevalence of deficiency has decreased dramatically.

Similar to these population-based trends, studies of hospital-based laboratories have shown a marked decrease in the rate of low serum and RBC folate levels, making for a very low pretest probability for folate deficiency (Table 1). Even before fortification had been fully implemented, a study of outpatients and inpatients cared for at 3 hospitals in Denver, Colorado in 1996 found that just $1.9 \%$ of patients had low serum folate levels and $4.4 \%$ had low RBC folate levels. ${ }^{17}$ A retrospective study of 26,662 patients in 1998 showed a rate of serum deficiency $(<2.7 \mathrm{ng} / \mathrm{mL})$ of $0.3 \%{ }^{18}$ The authors also found that despite a decline in rate of serum deficiency from $1.3 \%$ to $0.3 \%$ between 1994 and 1998, the total number of serum folate tests performed increased by $84 \%$. A similar study found just $0.4 \%$ of 1007 patients with low serum folate levels $(<3.0 \mathrm{ng} / \mathrm{mL}){ }^{7}$ Parallel results have been seen in other countries after implementation of folate fortification with a cohort of 2154 Canadian patients reporting low serum folate $(<6.8$ $\mathrm{nmol} / \mathrm{L})$ and $\mathrm{RBC}$ folate $(<417 \mathrm{nmol} / \mathrm{L})$ levels in just $0.5 \%$ and $0.7 \%$ of patients, respectively. ${ }^{19}$

Few studies have looked exclusively at hospitalized and emergency room patients. In an evaluation of 2093 serum folate tests performed on hospitalized or emergency room patients $(98.1 \%$ of whom were admitted) in 2011, only $2(0.1 \%)$ deficient levels $(<3$ $\mathrm{ng} / \mathrm{mL}$ ) were identified, 1 of which was associated with a macrocytic anemia. ${ }^{3}$ A similar study of RBC folate levels in 2562 patients at 3 Canadian hospitals found just $4(0.16 \%)$ levels to be low $(<254 \mathrm{nmol} / \mathrm{L})$, only 1 of which was associated with macrocytic anemia. ${ }^{20}$

When examining only patients with macrocytic anemia, the rates of folate deficiency are only slightly higher than the general population. As noted above, each of the 2 studies of inpatients uncovered just 1 patient with macrocytic anemia and concomitant low serum or RBC folate levels. ${ }^{3,20}$ Other studies reveal rates of serum folate deficiency in patients with macrocytic anemia and macrocytosis of $2.8 \%{ }^{7}$ and $1 \%,{ }^{21}$ respectively, and RBC folate deficiency rates in patients with macrocytosis of $1.8 \% .^{22}$ Patients with extreme macrocytosis $(\mathrm{MCV}>130)$ represent 1 subset of patients with a high pretest probability of low serum folate, with 1 study reporting low levels in $37 \%$ of patients. ${ }^{23}$

Despite the relatively inexpensive cost per serum and $\mathrm{RBC}$ folate test, expenses per test that result in an abnormally low level are significant. As the pretest probability for folate deficiency is extremely low, tests must be ordered on a large number of patients to find 1 patient with levels suggesting deficiency. For example, a study found that an institution charged $\$ 151$ per serum folate test, which amounted to $\$ 158,000$ per deficient result. ${ }^{3}$ The institutional cost was $<\$ 2.00$ per serum folate test and $<\$ 2093$ per deficient result. Another study reported the institutional cost of RBC folate to be $\$ 12.54$ per test and $\$ 8035$ per deficient result. ${ }^{20}$ The charges and costs are institution specific and will vary. However, in light of the low pretest probability of testing, any expense associated with these tests represents low value.

\section{WHAT YOU SHOULD DO INSTEAD}

The clinician in our case presentation is facing a common scenario-a patient with persistent anemia without a known etiology. The treatment of suspected or confirmed folate deficiency includes improving diet or adding a folic acid supplement, a low-cost (as little \$0.01 per tablet) intervention. Furthermore, other atrisk patients (eg, those with sickle cell disease, alcoholism, or malabsorption) may be candidates for long-term supplementation regardless of serum folate and/or RBC folate testing results. 
Folate deficiency in patients living in the United States and Canada is exceedingly rare, making the pretest probability of testing low. Furthermore, even patients with typical hematologic characteristics for folate deficiency (anemia and macrocytosis) are unlikely to have folate deficiency. Importantly, there are no nonhematologic indications to test for folate deficiency, and testing those patients, just as in the general population, yields an extremely low rate of folate deficiency. The tests themselves are unreliable and inaccurate, and fortunately, treatment is cheap, easy to administer, and can be done empirically. In other words, testing for folate deficiency is a "Thing We Do for No Reason."

\section{RECOMMENDATIONS}

In patients suspected of having folate deficiency or who are at high risk of folate deficiency (eg, diet poor in folate-rich or folic acid fortified foods), treat with a diet containing folate or folic acid fortified foods and/ or a supplement containing 400 to $1000 \mu \mathrm{g}$ of folic acid. Approximately 1 to 2 weeks following initiation of treatment, a complete blood count should be performed to evaluate for an appropriate increase in hematocrit/hemoglobin and decrease in $\mathrm{MCV} .{ }^{24}$ Once a full hematologic response is seen, treatment beyond this time is not required unless the cause (eg, malnutrition) persists.

Serum folate and RBC folate tests should not be routinely ordered. Even in those with macrocytic anemia, the pretest probability of folate deficiency remains low. Although testing may suggest a folate deficiency, it is still more likely there is another cause for the patient's anemia. This places providers at risk for premature closure. For patients such as the one presented in the case presentation, obtaining B12 levels is of greater importance, given the higher prevalence and the risks of untreated deficiency.

For patients in whom the pretest probability of folate deficiency is high (eg, those with an MCV $>130$ ), obtain fasting serum folate levels on samples taken before supplementation has begun or a diet administered.

Disclosures: Dr. Feldman is a consultant to Maven Medical, LLC. Maven Medical is a healthcare software startup.

Do you think this is a low-value practice? Is this truly a "Thing We Do for No Reason"? Share what you do in your practice and join in the conversation online by retweeting it on Twitter (\#TWDFNR) and Liking It on Facebook. We invite you to propose ideas for other "Things We Do for No Reason" topics byemailing TWDFNR@hospitalmedicine.org.

\section{References}

1. Lucock M. Folic acid: nutritional biochemistry, molecular biology, and role in disease processes. Mol Genet Metab. 2000;71(1-2):121138.

2. Herbert V. Experimental nutritional folate deficiency in man. Trans Assoc Am Physicians. 1962;75:307-320.

3. Theisen-Toupal J, Horowitz GL, Breu AC. Utility, charge, and cost of inpatient and emergency department serum folate testing. J Hosp Med. 2013;8(2):91-95.

4. Latif T, Hsi ED, Rybicki LA, Adelstein DJ. Is there a role for folate determinations in current clinical practice in the USA? Clin Lab Haematol. 2004;26(6):379-383.

5. Rachoin J-S, Cerceo E, Milcarek B, Hunter K, Gerber DR. Prevalence and impact of anemia in hospitalized patients. South Med J. 2013; 106(3):202-206.

6. Healthcare Cost and Utilization Project (HCUP). HCUP facts and figures: statistics on hospital-based care in the United States, 2009. Rockville, MD: Agency for Healthcare Research and Quality; 2011.

7. Ashraf MJ, Cook JR, Rothberg MB. Clinical utility of folic acid testing for patients with anemia or dementia. J Gen Intern Med. 2008; 23(6):824-826.

8. Gilfix BM. Utility of measuring serum or red blood cell folate in the era of folate fortification of flour. Clin Biochem. 2014;47(7-8):533538.

9. Humes HD. Kelley's Textbook of Internal Medicine. Philadelphia, PA: Lippincott Williams \& Wilkins; 2000.

10. Shojania AM. Problems in the diagnosis and investigation of megaloblastic anemia. Can Med Assoc J. 1980;122(9):999-1004.

11. Snow CF. Laboratory diagnosis of vitamin B12 and folate deficiency: a guide for the primary care physician. Arch Intern Med. 1999; 159(12):1289-1298.

12. Jaffe JP, Schilling RF. Erythrocyte folate levels: a clinical study. Am J Hematol. 1991;36(2):116-21.

13. US Food and Drug Administration. Food standards: amendments of standards of identity for enriched grain products to require addition of folic acid. Fed Regist. 1996;61:8781-8797.

14. Quinlivan EP, Gregory JF. Effect of food fortification on folic acid intake in the United States. Am J Clin Nutr. 2003;77(1):221-225.

15. Choumenkovitch SF, Selhub J, Wilson PWF, Rader JI, Rosenberg IH, Jacques PF. Folic acid intake from fortification in United States exceeds predictions. J Nutr. 2002;132(9):2792-2798.

16. Honein MA, Paulozzi LJ, Mathews TJ, Erickson JD, Wong LY. Impact of folic acid fortification of the US food supply on the occurrence of neural tube defects. JAMA. 2001:285(23):2981-2986.

17. Robinson AR, Mladenovic J. Lack of clinical utility of folate levels in the evaluation of macrocytosis or anemia. Am J Med. 2001;110(2): $88-90$.

18. Lawrence JM, Petitti DB, Watkins M, Umekubo MA. Trends in serum folate after food fortification. Lancet. 1999;354(9182):915-916.

19. Shojania AM, Kuster von K. Ordering folate assays is no longer justified for investigation of anemias, in folic acid fortified countries. BMC Res Notes. 2010;3:22.

20. Gudgeon P, Cavalcanti R. Folate testing in hospital inpatients. Am J Med. 2015;128(1):56-59.

21. Savage DG, Ogundipe A, Allen RH, Stabler SP, Lindenbaum J. Etiology and diagnostic evaluation of macrocytosis. Am J Med Sci. 2000; 319(6):343-352.

22. Joelson DW, Fiebig EW, Wu AHB. Diminished need for folate measurements among indigent populations in the post folic acid supplementation era. Arch Pathol Lab Med. 2007;131(3):477-480.

23. Planche V, Georgin-Lavialle S, Avillach P, et al. Etiologies and diagnostic work-up of extreme macrocytosis defined by an erythrocyte mean corpuscular volume over $130^{\circ} \mathrm{fL}$ : s study of 109 patients. Am J Hematol. 2014;89(6):665-666.

24. Smellie WSA, Wilson D, McNulty CAM, et al. Best practice in primary care pathology: review 1. J Clin Pathol. 2005;58(10):1016-1024. 